\title{
EXAMINATION OF THE ITERATIVE SERIES-EXPANSION METHOD FOR QUANTITATIVE TEXTURE ANALYSIS
}

\author{
D. RAABE \\ Institut für Metallkunde und Metallphysik, RWTH Aachen, \\ Kopernikusstr Str 14, 52056 Aachen, Germany
}

(Received 1 November 1994)

\begin{abstract}
Three-dimensional orientation distributions of grains in polycrystalline aggregates are referred to as crystallographic textures. Commonly, they are computed from two-dimensional centro-symmetric pole figures by employment of series expansion techniques or so called direct inversion methods. Both approaches lead to inaccuracies which are due to the absence of the odd coefficients and by truncation errors in the first case and to the under-determination of the set of linear equations combining cells in the pole figures and in the three-dimensional orientation space in the second case. For both types of calculation methods various correction procedures were suggested. In case of the series expansion methods the introduction of the non-negativity condition was reported to considerably improve the obtained solution. However, before large series of experimental data can be processed by such a method, its reliability has to be checked by use of analytical tools. Hence, in the present study a recently introduced iterative series-expansion method which accounts for the non-negativity condition is examined by use of standard functions.
\end{abstract}

KEY WORDS: Texture, iterative series expansion method, standard functions.

\section{INTRODUCTION}

For the investigation of the three-dimensional orientation distribution of the grains within a polycrystalline aggregate the orientation distribution function, $f(g)$, has to be reproduced from two-dimensional pole figures. For this purpose two basic concepts have been developed, namely, the series expansion methods and so called direct inversion methods.

In the conventional series expansion methods (Bunge 1965, Bunge 1982, Roe (1965), $\tilde{f}(g)$ is determined by computing the coefficients $C_{l}^{\mu v}$ of its orthogonal expansion from the expansion coefficients $\mathrm{F}_{l}^{v}\left(h_{i}\right)$ of experimentally detected pole figures. Since the centro-symmetric pole figures are expanded with a series of even order spherical harmonics, only the even order coefficients $C_{l}^{\mu v}$ of $f(g)$ are generated. As is also expressed by Friedel's law, the experimentally achieved pole figures reveal hence a higher symmetry than $f(g)$ in Euler space. The determination of the orientation distribution by the above mentioned methods (Bunge 1965, 1979, 1982) leads thus only to the even part of $f(g)$, which is referred to as $\tilde{f}(g)$. The complete function, $f(g)$, is named

Correspondence: Dr. D. Raabe, Institut für Metallkunde und Metallphysik, Rheinisch-Westfälische Technische Hochschule Aachen Kopernikusstr Str 14, 52056 Aachen, Germany. Tel: +49-241-806866/ 806855, Fax: +49-241-8888-301. E-mail: raabe@hpl.imm.rwth-aachen.de 
true orientation distribution function. The real orientation distribution is hence given by the equation $f(g)=\tilde{f}(g)+\tilde{f}(g)$, where $\tilde{f}(g)$ represents any function which can be added to $\tilde{f}(g)$ without changing corresponding projections, i.e. pole figures. The even function $\tilde{f}(g)$ usually causes texture dependent meaningless errors which are named ghost peaks. These adulterations can either be positive or negative.

The direct methods (Williams 1968, Ruer and Baro 1977, Imhof 1977, Matthies and Vinel 1982, Schaeben 1984, Pawlik 1986, Pawlik, Pospiech and Lücke 1991) utilize the discrete form of the fundamental equation for pole figure inversion, i.e. they work in the real space and not in the Fourier space. The solution is achieved by iteration. These approaches make use of the fact, that the discrete hemisphere of the pole figure corresponds to families of projection tubes in the $f(g)$ space, i.e. the non-negativity condition is intrinsically taken into account. However, also direct methods are affected by the inversion symmetry of the pole figure data, i.e. also in these methods ghost components are generated. In the discrete form, cells in the pole figures and in the $f(g)$ space are directly related by linear equations. The density in each pole figure cell is the sum of the corresponding cell densities in the $f(g)$ space. Since different $f(g)$ sums lead to the same pole density, the set of linear equations is underdetermined which leads to ghost errors. The second disadvantage is - inevitably connected with all direct approaches - the missing of Fourier coefficients which are desirable when technically anisotropic behavior such as directional elastic, magnetic or electrical properties of polycrystalline aggregates are aimed to be computed from texture data. Although directional physical properties need not necessarily be connected to Fourier coefficients, their employment permits high speed calculations of data of textured samples (Bunge 1970, Bunge 1979, Sowerby, Da Viana and Davies 1980).

For both types of calculation methods various correction procedures by which the appearance of ghost adulterations was claimed to be degraded have been suggested. In case of direct pole figure inversion the approach of arbitrary defined cells (ADC) has shown to provide solutions which are only weakly affected by ghost errors (Pawlik 1986, Pawlik and Pospiech 1987, Pawlik, Pospiech and Lücke 1991, Raabe and Lücke 1993).

In case of the series expansion techniques two methods for tackling ghost errors were suggested. In the approach proposed by Lücke et al. $\tilde{f}(g)$ is corrected by superimposing Gauss type scattering model functions (Lücke, Pospiech, Virnich and Jura, 1981, Hirsch and Lücke 1987). In the approximation pioneered by Bunge et al. the introduction of the non-negativity condition was proposed as adequate tool for yielding a degradation of ghost intensities (Bunge and Esling 1979, Bunge, Esling and Muller 1979, Esling and Bunge 1981, Dahms and Bunge 1989, Dahms 1992). However, before large series of experimental data are processed by such an improved method, its reliability has to be checked by use of analytical tools. Hence, in the present study a recently introduced iterative series-expansion method (Dahms and Bunge 1989, Dahms 1992) which accounts for the non-negativity condition is examined by use of so called standard functions (Matthies 1980, Matthies, Vinel, Helming 1987, 1988, 1990).

\section{APPLIED METHODS}

In the present work an iterative series-expansion method for pole figure inversion (Dahms and Bunge 1989, Dahms 1992), hereafter referred to as ISEM, which accounts 
for the non-negativity condition as well as for the so called phone-concept (Matthies 1984, Dahms 1992) was investigated with respect to the occurrence of ghost components. The first ingredient added to the conventional Fourier method of pole figure inversion, referred to as non-negativity condition, means that negative pole densities are physically senseless. The second condition included, referred to as phone concept (Matthies 1984), increases the non-negativity constraint in such a way that the minimum pole density should at least be equal not only to zero but to the pole density of an isotropic scattering texture component $r$ (phone). That means, whereas in the conventional iterative series expansion method negative pole densities were set to zero, in the presently employed version (Dahms 1992) they are set to r. Details of the technique employed were thoroughly discussed elsewhere (Bunge and Esling 1979, Dahms and Bunge 1989, Dahms 1992). For the present study the computer version of the ISEM, as outlined by Dahms (1992) was employed.

Since all calculation methods for the approximation of $f(g)$ from centro-symmetric pole figures lead merely to $\tilde{f}(g)$, a direct comparison of various techniques is of little sense. For the investigation of the accuracy of ISEM hence the ghost sensitive method of Matthies (Matthies 1980, Matthies, Vinel, Helming 1987, 1988, 1990) which makes use of analytically closed standard functions was employed as mathematical tool. The application of standard functions permits the calculation of pole figures as well as of the true orientation distribution function, $f(g)$, instead of only $f(g)$ if the occurring texture components are given. For this purpose artificial texture components were assembled. Both, $f(g)$, as well as the pole figures were thus computed from a set of identical Gauss type scattering texture components. In order to focus on textures of face centered cubic crystals (fcc), four different incomplete pole figures $\{111\},\{200\},\{220\}$ and $\{113\}$ were computed. According to the resolution typically used for conventional $X$-ray pole figure measurements, the pole inclination, $\alpha$, was changed from $5^{\circ}$ to $85^{\circ}$ in $5^{\circ}$ steps, i.e. so called incomplete pole figures were mathematically generated. Accordingly the pole azimuth, $\beta$, was varied within the range, $0^{\circ}$ and $360^{\circ}$ in $5^{\circ}$ steps. From these incomplete pole figure data the even part $\tilde{f}(g)$ of the orientation distribution function was calculated to a series expansion degree of $1_{\max }=22$ according to the conventional series expansion method (Bunge 1965, 1969, 1982). For the computation also of higher terms a higher resolution of the given pole figures would have been required. Subsequently, for the approximation of a ghost free orientation distribution function, the ISEM was employed.

In order to finally concede an objective comparison, $f(g)$ was additionally computed by using identical analytical standard components as employed for the computation of the pole figures which were subsequently processed by the ISEM. In all cases texture components with a scatter width of $15^{\circ}$ were used. In the present study four texture components which frequently occur in rolled or annealed fcc metals were investigated, namely the Cube $\{001\}<100>$, the Brass (B) $\{011\}<211>$, the Copper C $\{112\}<111>$ and the $S\{123\}<634>$ component. Owing to the cubic crystal symmetry (fcc) and the orthorhombic sample symmetry stemming from rolling (rolling direction, normal direction and transverse direction) the textures were treated in the reduced Euler space, revealing an expansion of $\pi / 2$ parallel to each Euler angle axis $\varphi_{1}, \phi$ and $\varphi_{2}$. The computed orientation distributions, i.e. $\tilde{f}(g), f(g)_{\text {ISEM }}$ and $f(g)_{\text {Standard }}$ are depicted in $\varphi_{2}$ - section through the reduced Euler space. Some important crystallographic orientations and texture fibers relevant for fcc textures are shown in Figure 1. 


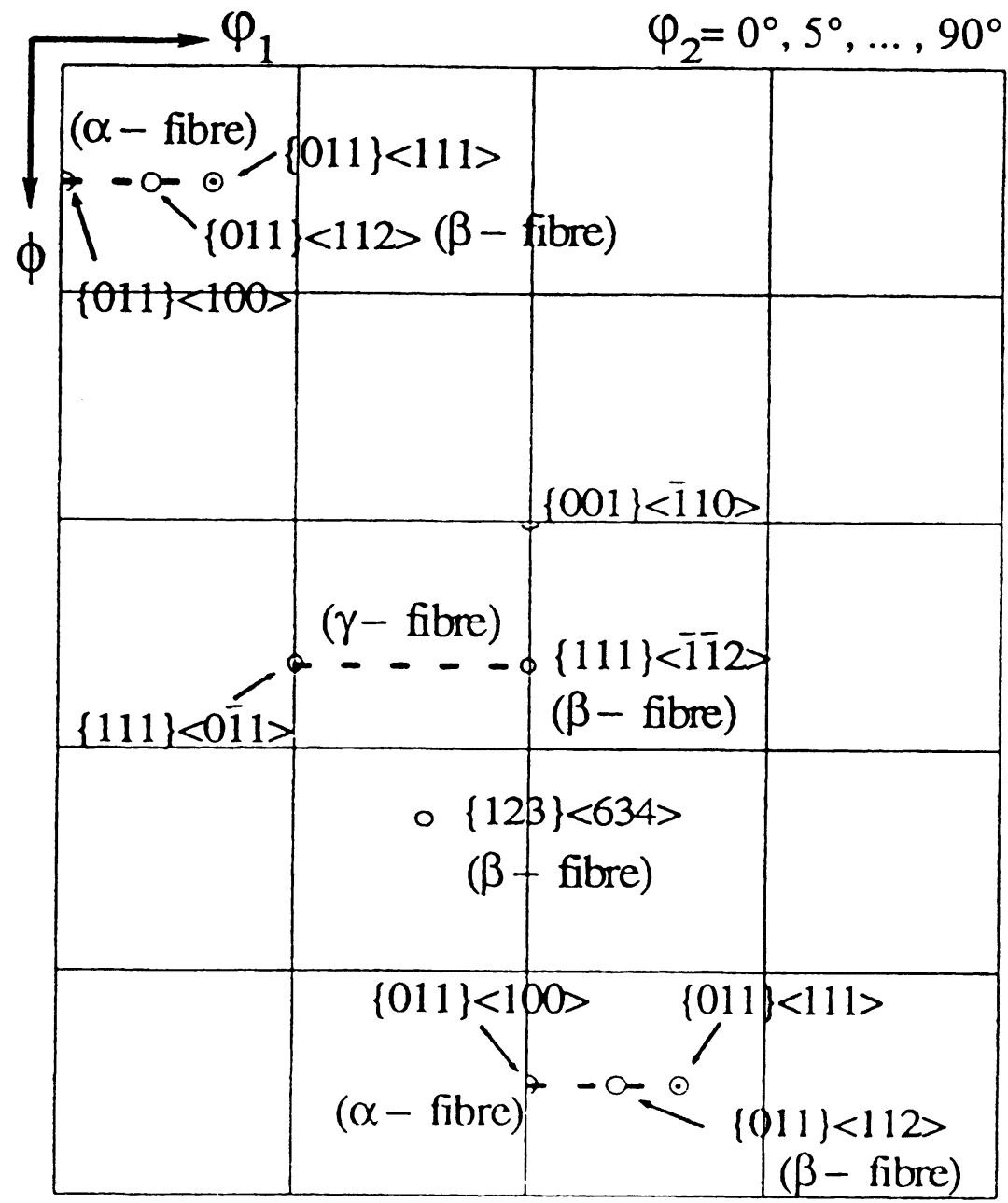

Figure 1 Schematical presentation of some relevant texture fibres and components depicted in $\varphi_{2}$ - sections through the reduced Euler space.

\section{RESULTS AND EVALUATION}

For all four components investigated the texture maximum increases in the following manner: $\tilde{f}(g), f(g)_{\text {ISEM }}$ and $f(g)_{\text {Standard }}$. The cube texture, $\tilde{f}(g)$, computed by used of only even coefficients from standard pole figures reveals a maximum of 97, Figure 2a, However, strong ghost peaks with an orientation density of about $10 \%$ relative to the maximum occur. The strongest ghost components appear as cube orientations either rotated about the normal or about the rolling direction. As is evident from Figure $2 b$ the orientation distribution function computed by the ISEM yields first, a much stronger maximum of the texture $\left(f(g)_{\max }=136\right)$ and second, no ghost adulterations. The ISEM 
ITERATIVE SERIES-EXPANSION METHOD

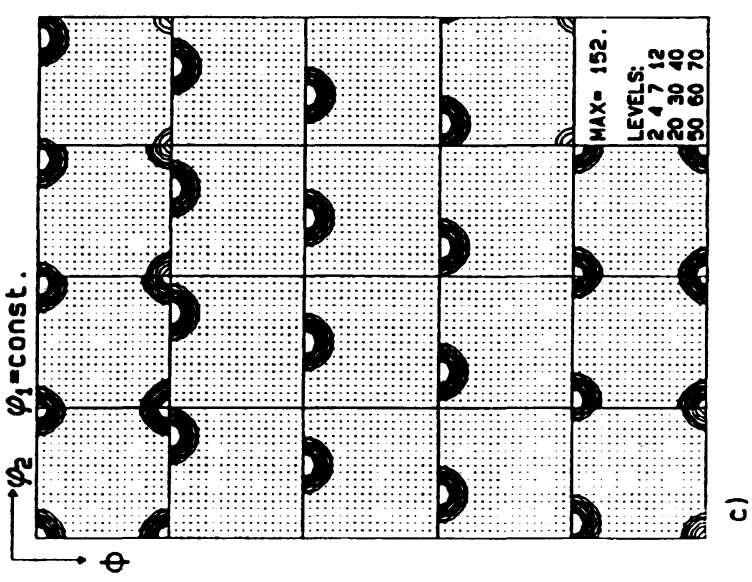

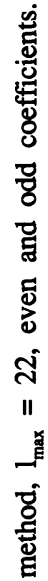

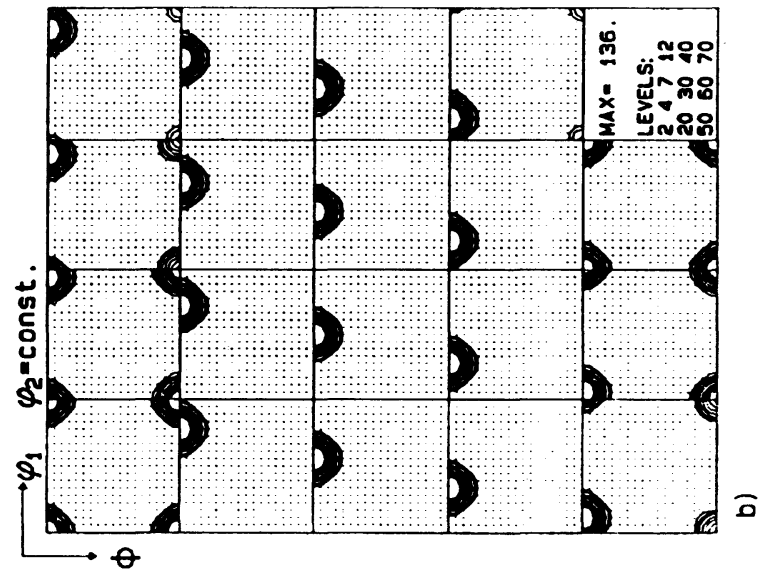

혼응

范

해

옹

胥总 壳

도

융형

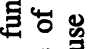

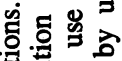

卷焉

๙

․ㅗ윯융

ఫัّ

응 도열

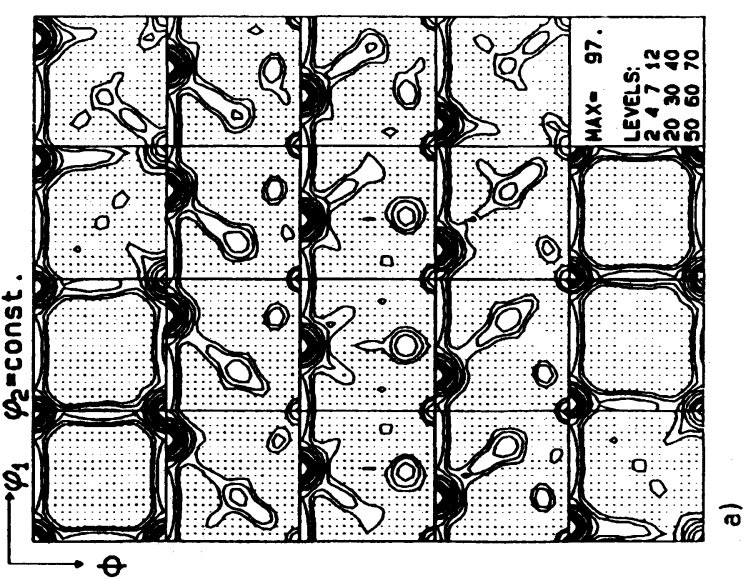

웜

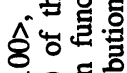

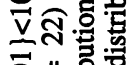
8 " 들

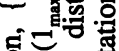

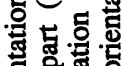
형롤

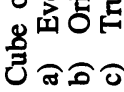

产 
thus provides a result very similar to the analytical texture which is computed by use of standard functions, Figure 2c. The main difference is that the texture maximum computed by use of standard functions, Figure $2 c,\left(f(g)_{\max }=152\right)$ slightly exceeds that one predicted by the ISEM, Figure $2 b$. This deviation is, however, attributed to the here applied series expansion degree of $1_{\max }=22$. It is well established that higher degrees of the series expansion lead to a higher texture maximum. Furthermore, the missing $0^{\circ}$ and $90^{\circ}$ inclination circles of the initial standard pole figures are assumed to contribute to the degradation of the texture maximum. The constraint of using incomplete rather than complete pole figures was imposed in order to check the validity of the ISEM for the processing of experimental data stemming from X-ray measurements.

Similar observations as revealed for the Cube component, Figure 2, also apply for the B orientation, Figure 3. Whereas the even part of the orientation distribution function, $\tilde{f}(g)$, yields a texture maximum of 54 and a considerable contribution of ghost components, Figure $3 a$, the texture which is computed by the ISEM, Figure $3 b$, shows a maximum of 68 and no ghost adulterations. This is evident by comparing the texture provided by the ISEM, Figure $3 b$, with the corresponding standard texture, Figure $3 c$. The difference of the texture maxima is attributed to the series expansion degree of 22 and to the application of incomplete pole figures. The use of higher series expansion degrees, however, would accordingly require to increase the resolution of the underlying pole figure grid which was artificially set to $5^{\circ} \times 5^{\circ}$ in order to simulate the resolution typically used when X-ray or neutron diffraction experiments are carried out.

The C orientation, Figure 4, which is a texture component frequently observed to dominate fcc rolling textures causes numerous minor ghost adulterations when only the even part of the orientation distribution function is generated, Figure 4a. As observed for the B component, Figure 3, also in case of the $\mathrm{C}$ orientation the texture obtained by the ISEM, Figure $4 \mathrm{~b}$, is very similar to that which is computed by use of standard functions, Figure $4 \mathrm{c}$. The maximum of $f(g)_{\text {ISEM }}$ is - as in the preceding examples about $10 \%$ lower as compared to that of $f(g)_{\text {Standard }}$. For the $S$ orientation which is together with $\mathrm{B}$ and $\mathrm{C}$ - the third relevant rolling component of fcc metals, the same applies, Figure 5. However, albeit the same Gauss type scattering function was employed for the $S$ component (scatter width $=15^{\circ}$ ) the absolute texture maximum is considerably weaker $\left(f(g)(I S E M)_{\text {max }}=32.3, f(g)(\text { Standard })_{\text {max }}=35\right)$ than that computed for B, Figure 3 , and $\mathrm{C}$, Figure 4. This deviation is attributed to the multiplicity of the $S$ orientation in Euler space being twice as high as that of $\mathrm{B}$ and $\mathrm{C}$ owing to its lower symmetry. This applies also for the Cube component, Figure 2, the multiplicity of which is even four times lower than that of S, Figure 5 .

As was discussed in the overview paper summarizing the panel discussion held on the 8th ICOTOM conference in Santa Fe (Wenk, Bunge, Kallend, Lücke, Matthies, Pospiech and Van Houtte 1988) not only the similarity of competing ODFs but additionally the quality of the recalculated pole figures must be taken into account. For this purpose the $\{111\}$ pole figures were recalculated from the ISEM ODFs (Figures $2 b, 3 b, 4 b, 5 b)$ within the range of the pole inclination from $5^{\circ}$ to $85^{\circ}$.

In case of the cube orientation the difference between the maximum pole density provided by the starting pole figure, Figure $6 \mathrm{a}$, and that yielded by the recalculated ISEM pole figure, Figure $6 \mathrm{~b}$, amounts to about $4 \%$. In Figure $6 \mathrm{c}$ the corresponding difference pole figure which has a maximum of 0.7 (3.5\%, referred to the maximum of the starting pole figure) and a minimum of $-0.09(0.5 \%$, referred to the maximum of the starting pole figure) is shown. In case of the B orientation, Figure 7, the maximum 
ITERATIVE SERIES-EXPANSION METHOD

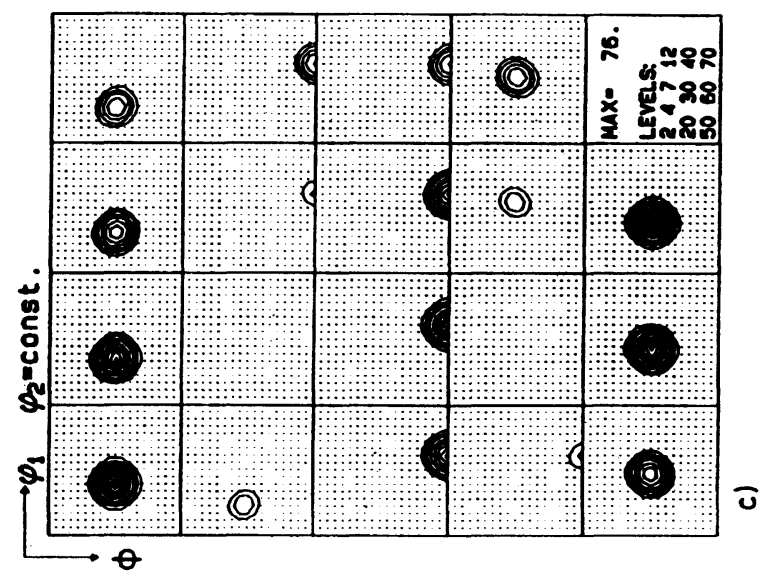

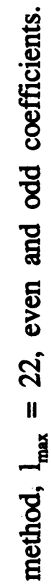

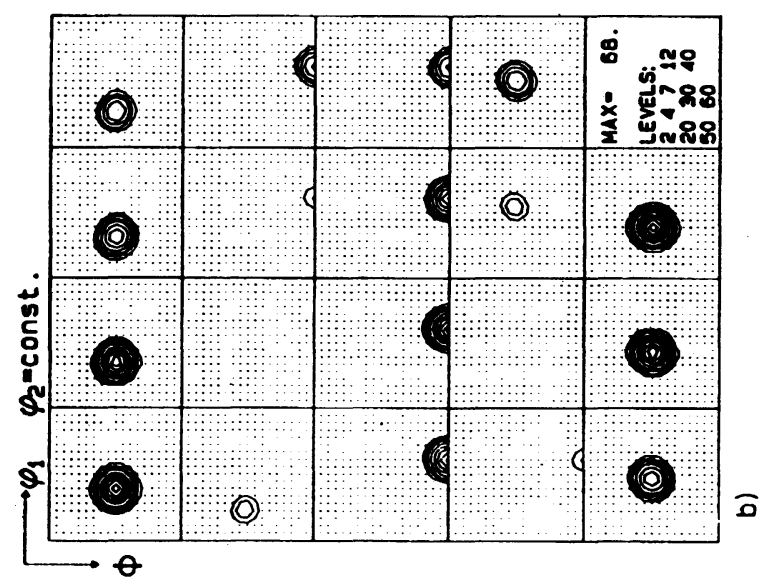

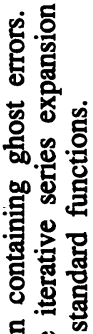

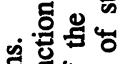

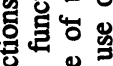

巡氙

1 今े

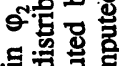

들 영

迩递

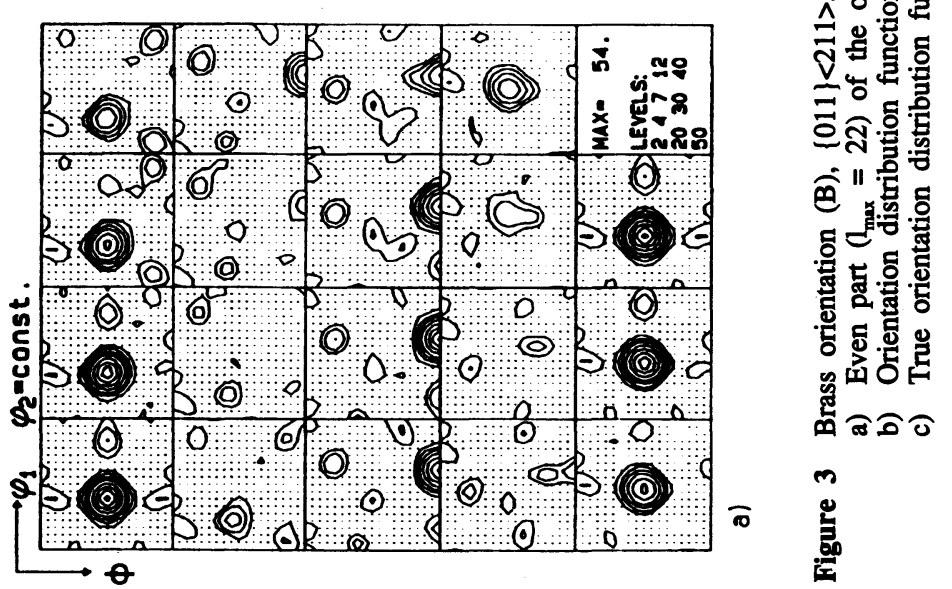




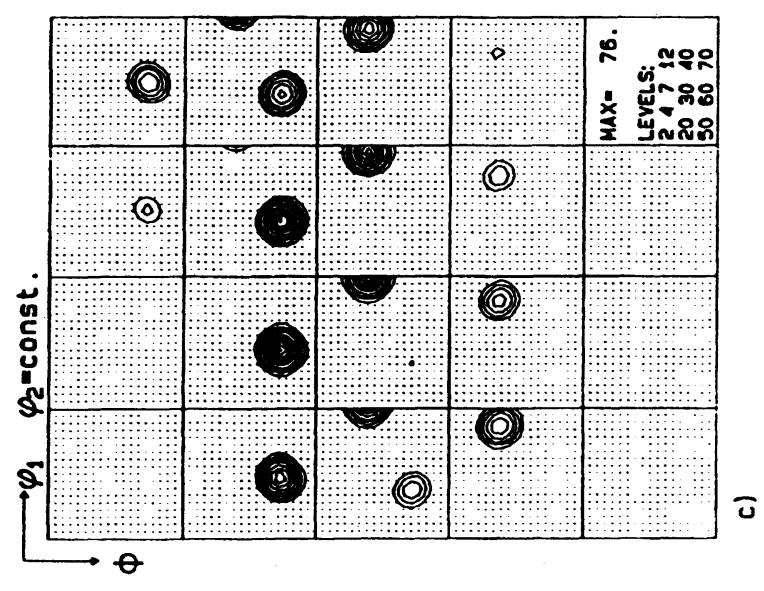

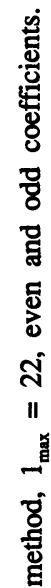

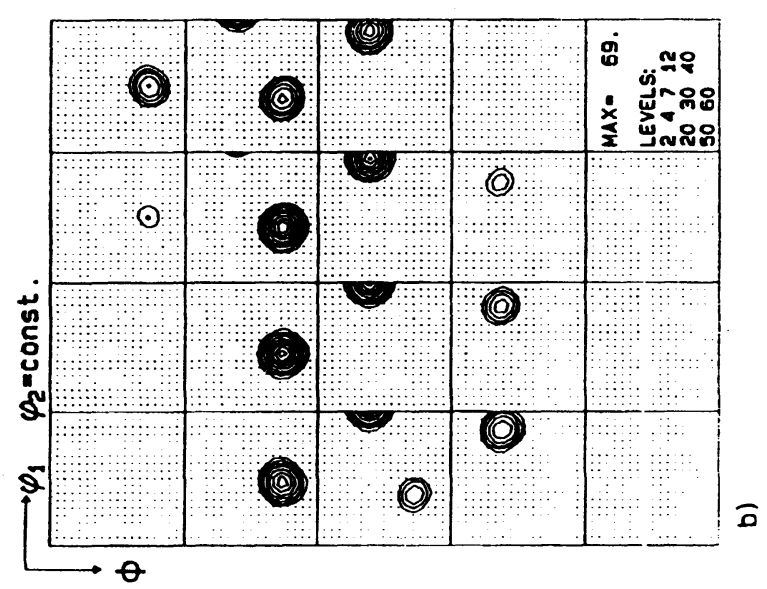

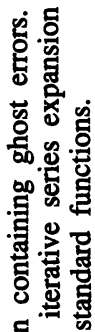

总总焉岁

1 을 중

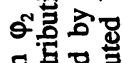

. 5 氞总

ชั

형

슨형혈

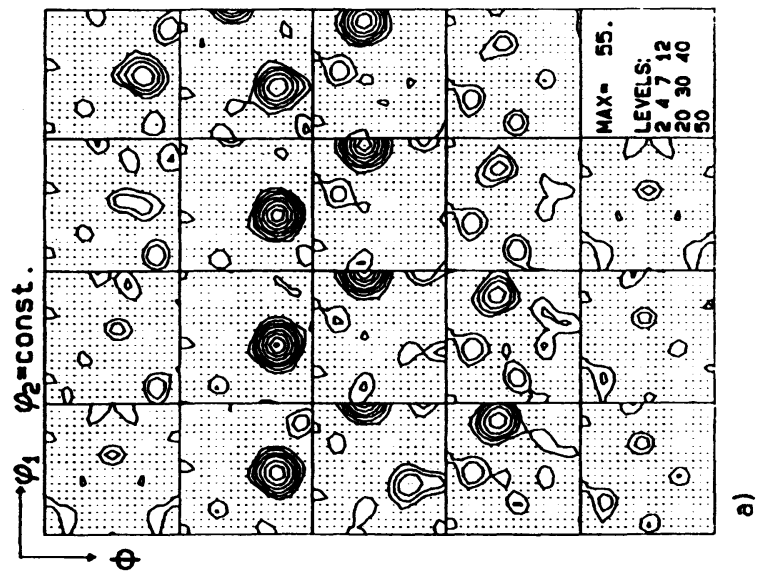

v

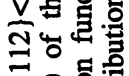

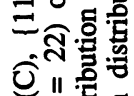

을

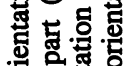

동

跑焉

ชั่งวิ

竞 
ITERATIVE SERIES-EXPANSION METHOD

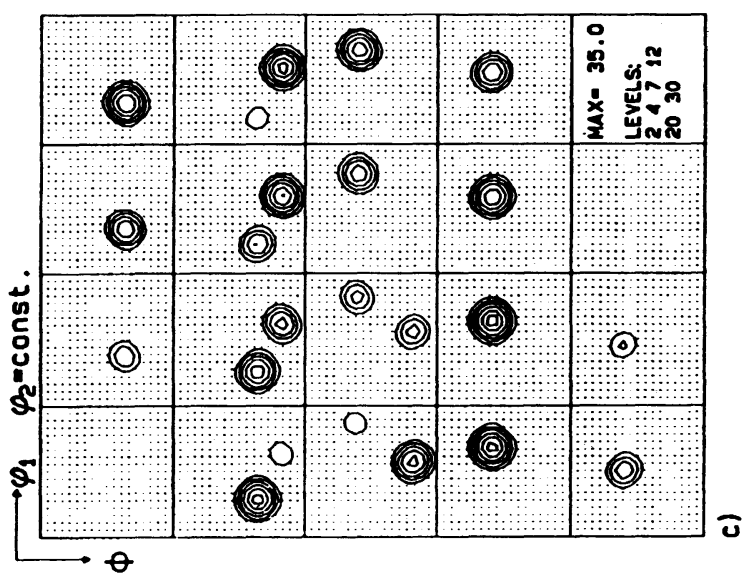

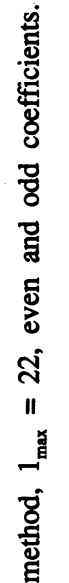

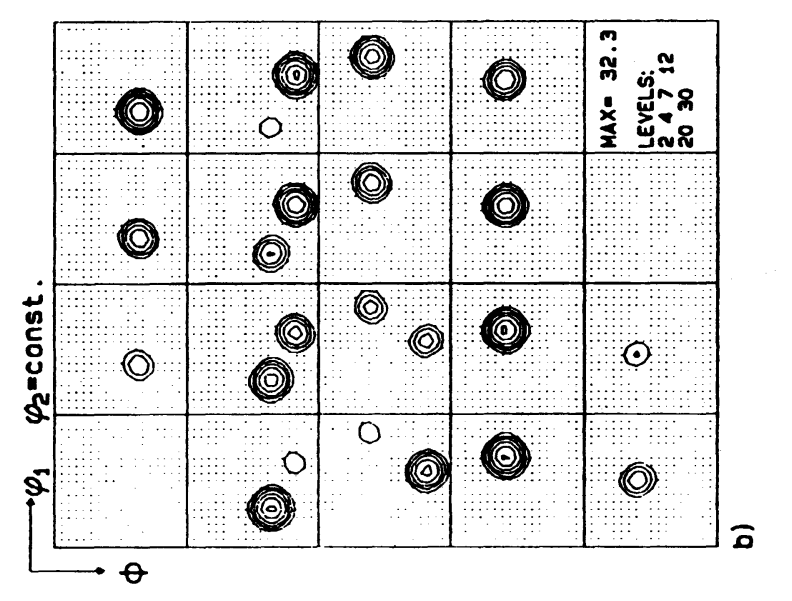

它.

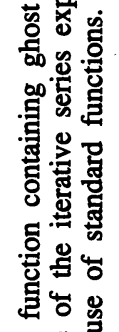

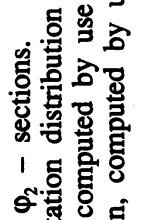

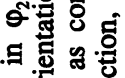

영 돌

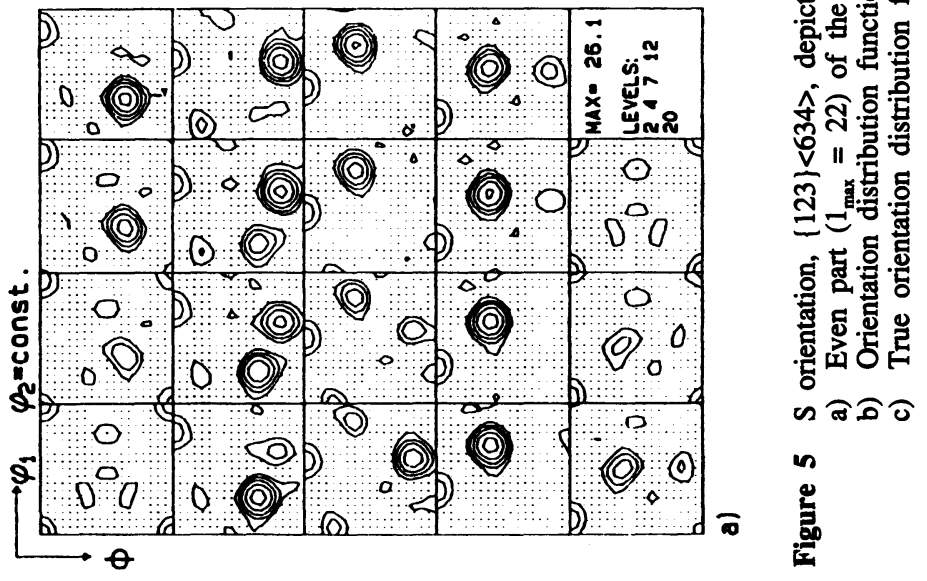




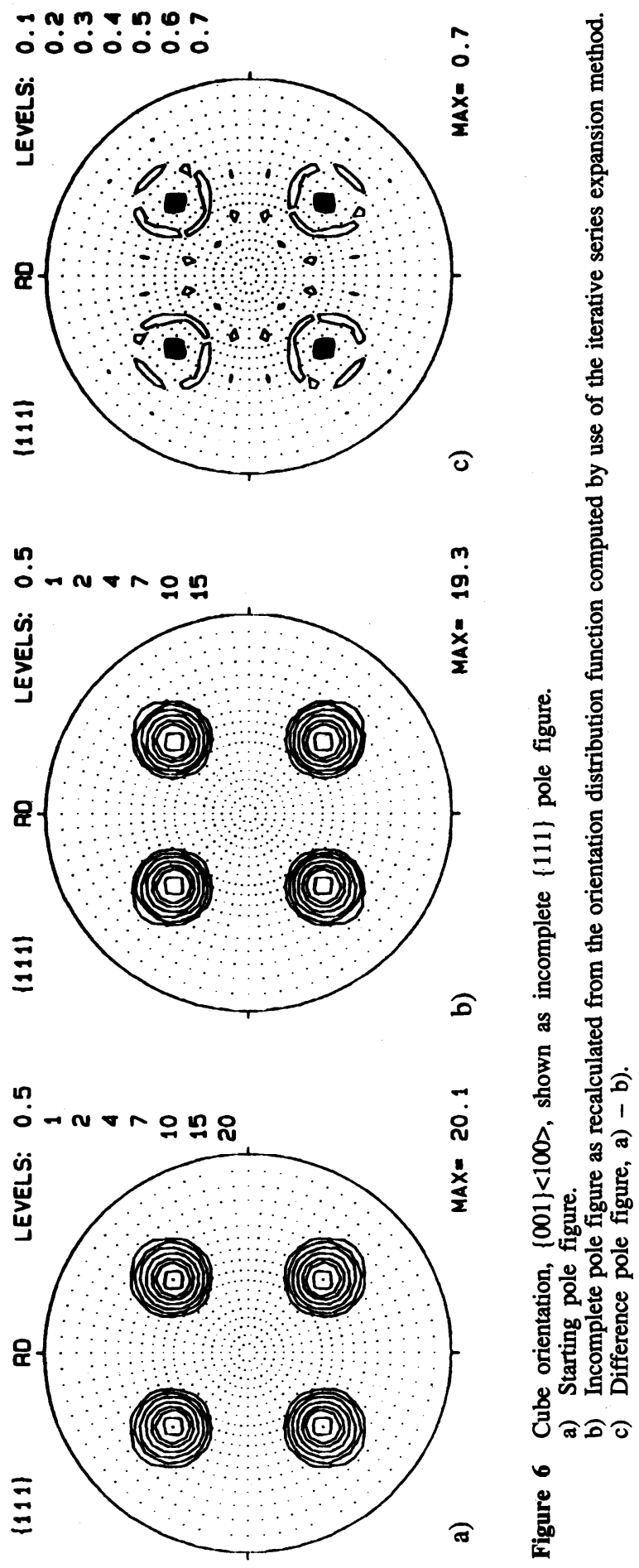



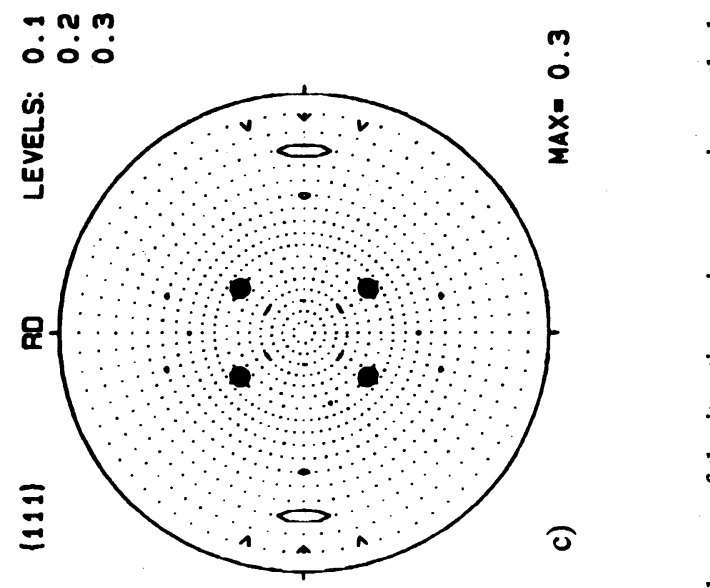

ర્ठ
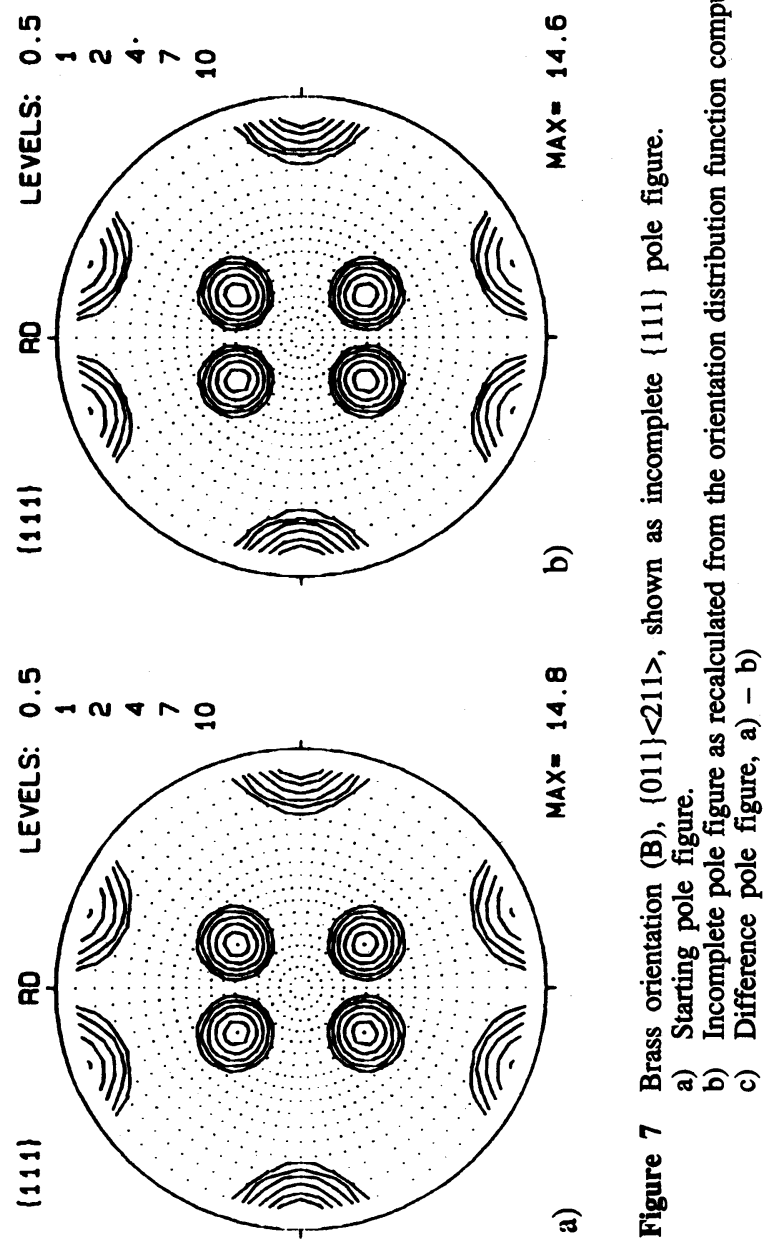


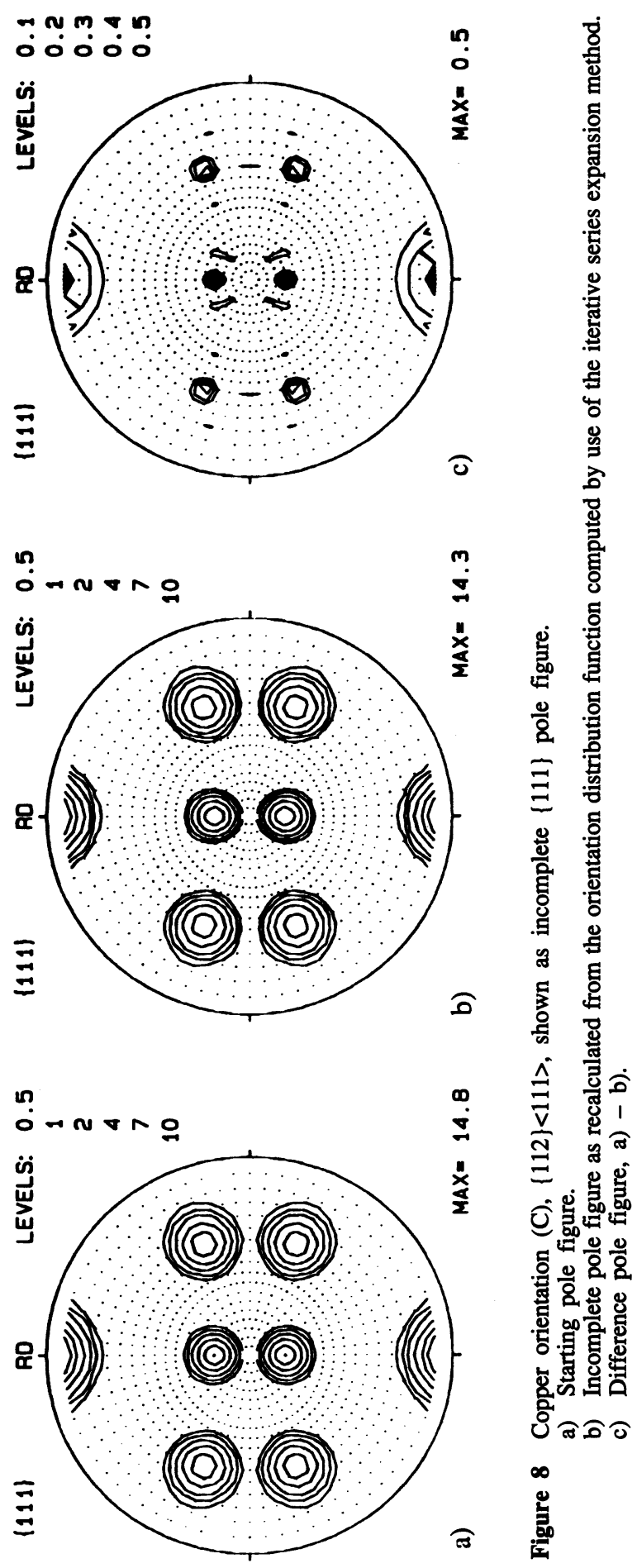




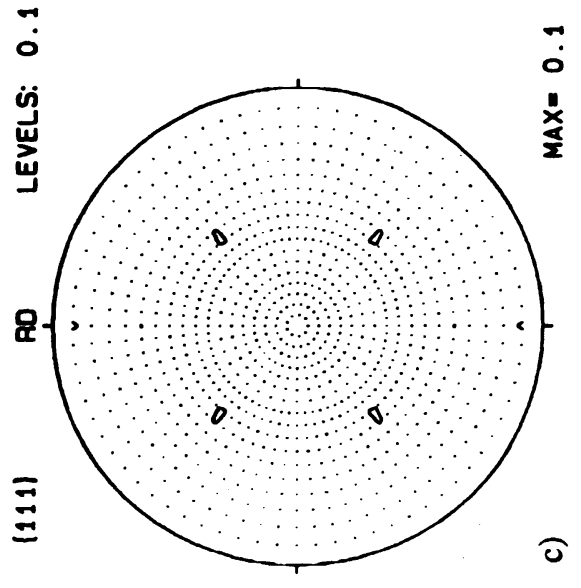

ర్ర

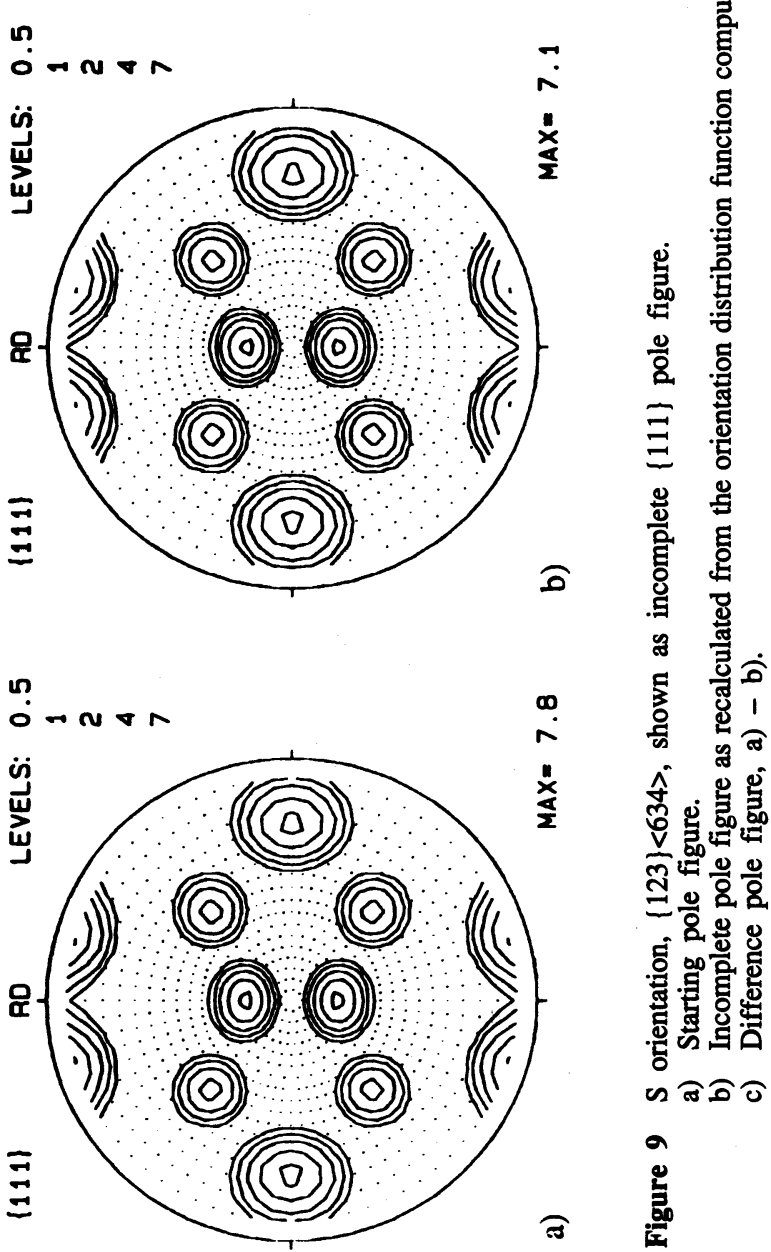


orientation density provided by the pole figures deviates by about $1.4 \%$. The minimum of the difference pole figure amounts to $-0.12(0.8 \%)$. For the $C$ orientation. Figure 8 , and the $S$ orientation, Figure 9, very similar deviations occur.

\section{CONCLUSIONS}

- The iterative series-expansion method (ISEM) for pole figure inversion which accounts for the non-negativity condition as well as for the phone-concept was quantitatively investigated by use of standard functions with respect to the occurrence of ghost errors.

- Four important texture components frequently observed in orientation distributions of fcc metals were examined.

- The textures under investigation were artificially generated by use of standard functions (pole figures and orientation distribution functions). From four standard pole figures the orientation distribution was computed by use of the ISEM. The results were compared to the orientation distribution functions determined by means of standard functions.

- No ghost adulterations caused by the ISEM were detected for the textures examined.

- The textures approximated by the ISEM were slightly weaker than the corresponding standard ODFs. This deviation was attributed to the low series expansion degree employed.

\section{Acknowledgements}

The author is grateful to $M$. Dahms for providing the source code four using the ISEM method and to G.W. Vinel and S. Matthies for contributing the software for the employment of standard functions.

\section{References}

Bunge, H. J. (1982). Texture Analysis in Materials Science, Butterworths, London.

Bunge, H. J. (1965). Zeit. Metallkunde, 56, 872.

Bunge, H. J. (1979). Zeit. Metallkunde, 70, 411.

Bunge, H. J. and Esling C. (1979). J. Physique-Lettr., 40, 627.

Bunge, H. J., Esling C. and Muller J. (1979). J. Appl. Cryst., 13, 544.

Bunge, H. J. (1970). Kristall u. Technik, 5, 145.

Bunge, H. J. (1969). Mathem. Meth. der Texturanalyse, Berlin, Akademie Verlag.

Dahms, M. and Bunge, H. J. (1989). J. Appl. Cryst., 22, 439.

Dahms, M. (1992). Text. and Microstr., 19, 169.

Esling, C. and Bunge, H. J. (1981). J. Physique-Lettr., 42, 141.

Hirsch, J. and Lücke, K. (1987). in "Theo. Meth. of Tex. Anal." ed. Bunge, H. J. DGM Informationsgesellschaft Verlag, 53.

Imhof, J. (1977). Zeit. Metallkunde, 68, 38.

Lücke, K., Pospiech, J., Virnich, K. H. and Jura, J. (1981). Acta Met., 29, 167.

Matthies, S. and Vinel, G. W. (1982). Phys. Stat. Sol., (b) 112, K111.

Matthies, S. (1980). Phys. Stat. Sol., (b), 101, K111.

Matthies, S., Vinel, G. W. and Helming, K. Standard Distributions in Text. Anal., Vol. I (1987), Vol. II (1988), Vol. III (1990), Berlin, Akademie Verlag.

Matthies, S. (1984). Proc. ICOTOM 7, ed. C. M. Brakman, P. Jongenburger and E. J. Mittenseijer, Netherl. Soc. for Mater. Sci., Noordwijkerhout, 737.

Pawlik, K., Pospiech, J. (1987). in Theo. Meth. of Tex. Anal., ed. Bunge, H. J. DGM Informationsgesellschaft Verlag, 53.

Pawlik, K. (1986). Phys. Stat. Sol., (b), 134, 477. 
Pawlik, K., Pospiech, J. and Lücke, K. (1991). Proc. ICOTOM 9, Text. a. Micro., ed. Bunge, H. J., $14,25$.

Raabe, D. and Lücke, K. (1993). Phys. Stat. Sol., (b), 180, 59.

Roe, R. (1965). Journ. Appl. Phys., 36, 2024.

Ruer, D. and Baro, R. (1977). Adv. X-ray Anal., 20, 187.

Schaeben; H. (1984). Phys. Stat. Sol., (b), 123, 425.

Sowerby, R., Da Viana, C. S. and Davies, G. J. (1980). Mat. Sc. Eng., 23, 23.

Wenk, H., Bunge, H. J., Kallend, J., Lücke, K., Matthies, S., Pospiech, J. and van Houtte, P. (1988).

Proc. ICOTOM 8, eds. Kallend, J. and Gottstein, G., The Metall. Soc., 17.

Williams, R. D. (1968). Journ. Appl. Phys., 39, 4329. 